\title{
Temporal Gene Expression in the Hippocampus and Peripheral Organs to Endotoxin-Induced Systemic Inflammatory Response in Caspase-1-Deficient Mice
}

\author{
Claudio Alberto Mastronardi ${ }^{a}$ Gilberto Paz-Filho ${ }^{\text {a }}$ Martina Zanoni ${ }^{c}$ \\ Nicolas Molano-González ${ }^{d}$ Mauricio Arcos-Burgos ${ }^{a}$ Julio Licinio ${ }^{b}$ Ma-Li Wong ${ }^{b}$ \\ ${ }^{a}$ Genomics and Predictive Medicine Group, Genome Biology Department, John Curtin School of Medical Research, \\ Australian National University, Canberra, A.C.T., and ${ }^{\mathrm{b}}$ Mind and Brain Theme, South Australian Health and Medical \\ Research Institute and Flinders, University of South Australia, Adelaide, S.A., Australia; ' Department of Psychiatry, \\ University of Verona, Verona, Italy; ${ }^{\mathrm{d} C e n t e r}$ for Autoimmune Diseases Research (CREA), School of Medicine and Health \\ Sciences, Universidad del Rosario, Bogotá, Colombia
}

\section{Key Words}

Inflammation - Lipopolysaccharide - Transcription .

Nos2 $\cdot$ Cox2 $\cdot$ Chemokines $\cdot$ Cxcl1 $\cdot$ Cxcl10 - Adamts 1 .

Coexpression

\begin{abstract}
Objectives: Caspase-1 (casp1), a key protease involved in the systemic inflammatory response syndrome (SIRS), controls the brain expression of a set of eight genes: Nos2 and Ptgs2 (nitric oxide synthase 2 and prostaglandin-endoperoxide synthase 2, two inducible enzymes), $C x \mathrm{Cl} 1$ and $\mathrm{CxCl10}$ (C-X-C motif chemokine ligand 1 and ligand 10), Tgtp and Gbp2 ( $T$ cell-specific GTPase 1 and guanylate-binding protein 2, two GTPases), Adamts 1 (a disintegrin-like and metallopeptidase with thrombospondin type 1 motif, 1, a metalloprotease) and $/ 11 r n$ (interleukin-1 receptor antagonist). Our objective was to ascertain whether casp1 also controlled the peripheral expression of these genes and, if so, to compare their central versus peripheral patterns of gene expression in immune and endocrine tissues during SIRS. Methods: Wildtype (wt) and casp1 knockout (casp $1^{-/-}$) mice were injected
\end{abstract}

with either saline or a high dose of endotoxin/lipopolysaccharide (LPS; $800 \mu \mathrm{g} / \mathrm{mice}$ i.p.). Saline-injected mice were immediately euthanized after injection, whereas LPS-injected mice were sacrificed 6 and $12 \mathrm{~h}$ after LPS administration. Hippocampal, splenic and adrenal gene expressions were determined by real-time PCR. Results: Overall, casp $1^{-/}$mice showed a lower inflammatory response than wt mice. The expression levels of powerful proinflammatory factors such as Nos2 and Ptgs 2 was reduced in casp $1^{-/-}$mice. Moreover, a hierarchical clustering analysis aimed at studying patterns of gene coexpression revealed large alterations in the hippocampal pattern of $\mathrm{casp}^{-/-}$mice. Surprisingly, the expression of Adamts 1 was increased in the hippocampus and adrenals of casp $1^{-1-}$ mice. Conclusions: The resilience of casp $1^{-/-}$mice to SIRS lethality is associated with a lower inflammatory response, loss of hippocampal gene coexpression patterns, and increased hippocampal Adamts 1 gene expression. The latter might be beneficial for casp $1^{-/-}$mice, since ADAMTS1 is likely to play a role in neuronal plasticity. The mechanisms described here may help the development of either novel biomarkers or therapeutic targets against SIRS/sepsis.

(c) 2015 S. Karger AG, Basel

\section{KARGER 125}

(c) 2015 S. Karger AG, Base

$1021-7401 / 15 / 0224-0263 \$ 39.50 / 0$ 


\section{Introduction}

Systemic inflammatory response syndrome (SIRS) defines a serious medical condition of extreme and severe generalized inflammation in the absence of infection, whereas infection is the underlying process in sepsis [1]. Both SIRS and sepsis are leading causes of death in intensive care units [2].

The molecular mechanisms underlying SIRS remain elusive and, consequently, effective therapeutic strategies have not yet been developed. Animal models have been developed to aid the elucidation of the pivotal role of the innate immune system on SIRS [3-10], such as the administration of endotoxin/lipopolysaccharide (LPS) from Gram-negative bacteria to genetically engineered mouse strains in order to mimic the generalized inflammation present in SIRS $[11,12]$. One of these strains is the caspase-1 ( $\left.\operatorname{casp}^{-/-}\right)$knockout mouse that is resilient to LPSinduced lethality [11]. Casp1 is a cysteine protease that may be a crucial element in SIRS lethality. It cleaves prointerleukin (IL)-1 $\beta$ and pro-IL-18 into mature biologically active cytokines. By submitting casp $1^{-/-}$mice to LPSinduced SIRS, we previously observed that casp1 orchestrates the differential expression of eight genes in the central nervous system (CNS): two inducible enzymes [nitric oxide synthase 2 (Nos2) and prostaglandin-endoperoxide synthase 2 /cyclooxygenase 2 (Ptgs2)], two chemokines [C-X-C motif ligand 1 (Cxcl1) and 10 (Cxcl10)], two GTPases [T cell-specific GTPase (Tgtp) and guanylate nucleotide-binding protein 2 (Gbp2)], one metalloprotease [a disintegrin-like and metallopeptidase with thrombospondin type 1 (Adamts1)] and the IL-1 receptor antagonist gene (Ill rn), an endogenous antagonist of IL-1 [12].

Because SIRS is characterized by neuro-immuno-endocrine derangements leading to death [13-16], we focused our studies on neural (hippocampus), immune (spleen) and endocrine (adrenals) tissues of wild-type (wt; control) and casp1 $^{-/}$mice. The hippocampus was chosen because it is a brain area that plays a decisive role in the regulation of the HPA (hypothalamic-pituitary-adrenal) axis during different types of stress [17], including immunological challenges $[18,19]$. The adrenals are the effector organs of the HPA-axis and were studied because of their crucial role in the secretion of corticoids during SIRS, whereas the spleen was chosen for being a prominent immune organ.

Given the fact that many of the proinflammatory factors that are triggered during LPS-induced SIRS require de novo synthesis, we measured their mRNA expression before $(0 \mathrm{~h})$ and after LPS injection (6 and $12 \mathrm{~h}$ later). We hypothesized that their involvement in SIRS-induced lethality would be reflected by differential mRNA expression levels between wt (control) and casp $1^{-/-}$mice (resilient to SIRS-induced lethality).

We also assessed gene-gene interactions in wt and $\mathrm{casp}^{-/-}$mice and compared them to the patterns of gene expression in the CNS (hippocampal). Herein, we present evidence that a lower inflammatory response, pattern disruption of hippocampal gene coexpression of the aforementioned set of eight genes, and activation of hippocampal Adamts1 may be key mechanisms underpinning resilience to SIRS lethality in casp $1^{-/-}$mice.

\section{Materials and Methods}

\section{Animals}

We used virus- and antibody-free 8 to 10 -week-old male wt and

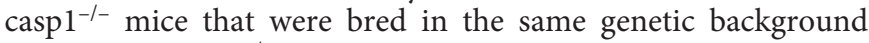
$(\mathrm{C} 57 \mathrm{BL} / 6)$. Casp $1^{-1-}$ mice were created, characterized and generously provided by BASF Bioresearch (Cambridge, Mass., USA) [11]. These mice are fertile, develop normally, and have no histopathological abnormalities. It is noteworthy that casp $1^{-/-}$mice are resistant to the lethal effects of LPS [11] as well as to the anorectic effects exerted by the central action of LPS-induced cytokines [20]. Mice were kept in a light- (12 h on/12 h off) and temperaturecontrolled environment, with food and water ad libitum. All procedures were performed under established guidelines for the humane care and use of animals; they were approved by the University of Miami Institutional Animal Care and Use, and the Australian National University Animal Experimentation Ethics Committee. Experiments were designed to avoid confounding variables such as infection and stress, which could alter mRNA levels.

\section{Experimental Protocol}

$\mathrm{Wt}$ and casp $1^{-/-}$mice $(\mathrm{n}=23$ per genotype) were injected with either $0.9 \% \mathrm{NaCl}$ (saline) or a lethal dose of LPS $(800 \mu \mathrm{g} /$ mice i.p. from Escherichia coli serotype O111:B4; Merk Millipore, Bayswater, Vic., Australia) [11]. Control animals were immediately euthanized after saline injection i.p. ( $0 \mathrm{~h}$; wt mice, $\mathrm{n}=7$, and $\mathrm{casp}^{-/-}$ mice, $n=8$ ), whereas LPS-injected mice were euthanized at $6 \mathrm{~h}$ (wt, $\mathrm{n}=13$, and casp $1^{-/-}, \mathrm{n}=12$ ), and $12 \mathrm{~h}$ (wt and casp $1^{-/-}, \mathrm{n}=3$ per genotype) after LPS injection. We chose to use the specific LPS serotype, dose and administration route because this regimen was previously shown to cause $100 \%$ lethality in wt mice during the first $36 \mathrm{~h}$ after injection [11]. Injections were given between 7.00 and 9.00 a.m.; mice were sacrificed by decapitation one at a time in a room distant from the animal holding area in a manner to avoid stress triggered by blood scent. Organs were extracted, snapfrozen and stored at $-80^{\circ} \mathrm{C}$ until processed.

\section{RNA Isolation and Reverse Transcription}

We chose one brain area (hippocampus) and two peripheral tissues (spleen and adrenals), to determine variations in central and peripheral mRNA expression levels. Total RNA was extracted from individual tissues using RNeasy Lipid Mini Kit including DNase digestion (Qiagen, Germantown, Md., USA) and quantified using 
Table 1. List of real-time PCR primers used to determine the gene expression levels of the eight selected genes

\begin{tabular}{llll}
\hline Gene & Forward & Reverse & NCBI Ref. Seq. \\
\hline B-actin & 5-CCTAGGCACCAGGGTGTGAT-3 & 5-CATGTCGTCCCAGTTGGTAACA-3 & NM_007393 \\
Ptgs2 & 5-TGGGCCATGGAGTGGACTT-3 & 5-GGATGTGAGGAGGGTAGATCATCT-3 & NM_011198.3 \\
Nos2 & 5-AAGGCCACATCGGATTCAC-3 & 5-TGTTCCTCTATTTTTGCCTCTTTAAAG-3 & NM_010927.3 \\
Cxcl1 & 5-ACCGAAGTCATAGCCACACTCA-3 & 5-CACCTTTAGCATCTTTTGGACAA-3 & NM_008176.3 \\
Cxcl10 & 5-CTGGGTCTGAGTGGGACTCAA-3 & 5-TCATTGCCACGATGAAAAAGAAT-3 & NM_021274.1 \\
Tgtp & 5-CACCACTGCTGAGCTTCTACCATA-3 & 5-TCGATGTCTCTCAGTACCTTTTCAA-3 & NM_011579.3 \\
Gbp 2 & 5-TTGAGAAGGGTGACAACCAGAA-3 & 5-TGGTTCCTATGCTGTTGTAGATGAA-3 & NM_010260.1 \\
Il-1ra & 5-CCAGCTGGAGGAAGTTAACATCA-3 & 5-ACGGTCAGCCTCTAGTGTTGTG-3 & NM_031167.5 \\
Adamts1 & 5-GACAATAACGGAAAAACGTTCAGA-3 & 5-GTGAGCTTGCACCTGTCCTTT-3 & NM_009621.4 \\
\hline
\end{tabular}

a Nanodrop ND-1000 spectrophotometer (Thermo-Fisher Scientific, Waltham, Mass., USA); $1 \mu \mathrm{g}$ of RNA was reverse transcribed to cDNA with the Omniscript RT Kit (Qiagen) using random hexamer primers (Invitrogen, Carlsbad, Calif., USA).

\section{PCR Primers}

The genes of interest were selected from our previous microarray study [12]. To avoid amplification of genomic DNA traces, forward and reverse primers were designed in different exons with Primer Express Software (Applied Biosystems, Foster City, Calif., USA). We used negative and positive controls (respectively, reverse transcription with genomic DNA and cDNA from mouse brain treated with LPS). Table 1 lists our primer pair sequences, which amplified cDNA only.

\section{Quantitative Real-Time PCR}

We performed SYBR green-based real-time PCR to determine variations in mRNA expression profiles. Standard curves of pooled, serially diluted cDNAs were constructed for each primer pair. Experiments were performed using the 7900HT Fast Real-Time PCR System (Applied Biosystems). cDNA samples were run in triplicates; SYBR green cycle threshold values were averaged for each sample, and the RNA input for each target gene was calculated using standard curves. Fold changes were expressed as a ratio to $\beta$-actin expression for each sample. Each reaction included cDNA from $20 \mathrm{ng}$ of RNA, 4.5 pmol of each primer, and $7.5 \mu \mathrm{l}$ of SYBR green PCR Mastermix (Applied Biosystems) in a final volume of $15 \mu$ l. The PCR parameters were: $50^{\circ} \mathrm{C}$ for $2 \mathrm{~min}, 95^{\circ} \mathrm{C}$ for $10 \mathrm{~min}, 40$ cycles of $95^{\circ} \mathrm{C}$ for $15 \mathrm{~s}$, and $60^{\circ} \mathrm{C}$ for $1 \mathrm{~min}$.

\section{Statistical Analysis}

Variance Analyses

Two-way ANOVA tests were performed to assess the effects of genotype (wt or casp $1^{-/-}$) and time $(0,6$ or $12 \mathrm{~h}$ ) both individually and in combination on gene expression levels in adrenal, hippocampus and spleen tissues. Tukey's honest significant difference test was used within each gene/tissue combination to perform pair-wise comparisons maintaining the family-wise probability of coverage at $95 \%$. We present $95 \%$ confidence intervals (CI) for the differences and family-wise-corrected $\mathrm{p}$ values to assess statistical significance. All analyses were performed in R package version 3.0.2 (R Foundation for Statistical Computing, 2013).

Gene Transcription Changes during Inflammatory Stress
Correlation Analysis

We calculated pair-wise Pearson's correlation coefficients to examine the relationships between gene expression in wt and casp $^{-1-}$ mice. As a complementary strategy, nonparametric local regressions (LOESS) were fitted to the data to assess the relationship between pair-wise gene expression levels. Statistical comparison of the linear correlation coefficient was performed based on a normal distribution, and the resulting $\mathrm{p}$ values were corrected using the false discovery rate [21].

\section{Hierarchical Clustering}

We used hierarchical clustering to analyze gene coexpression in our samples. Hierarchical clustering uses an agglomerative algorithm that joins the most similar component features, and then joins the next most similar using the first aggregation as a single combined unit. In hierarchical clustering, the clusters were generated via complete linkage. To assess the uncertainty of the analysis, approximately unbiased (AU) and bootstrap probability (BP) $\mathrm{p}$ values were calculated by pvclust [22], $\mathrm{R}$ package version 3.0.2. AU p values were computed by multiscale bootstrap resampling, and are a better approximation to unbiased $p$ values than BP-based $\mathrm{p}$ values (computed by normal bootstrap resampling).

\section{Results}

\section{LPS-Induced Differential Temporal Gene Expression in Peripheral and Central Tissues of wt and casp $1^{-/-}$ Mice}

Our study was conducted up to $12 \mathrm{~h}$ after LPS injection. The health status of mice of both genotypes gradually worsened with the passage of time. Towards the last collection point, at $12 \mathrm{~h}$ after LPS injection, wt mice were quite immobile but without signs of being moribund (e.g. hard-labored breathing), whereas casp $1^{-/}$ mice were less active but still responsive to external stimuli such as a gentle tapping and/or shaking of the cage. We corroborated the resilience of $\mathrm{casp}^{-/-}$mice to 
Table 2. Survival rate of wt and $\mathrm{casp}^{-/-}$mice after receiving an $\mathrm{LD}_{100}$ injection of LPS

\begin{tabular}{llll}
\hline & $\mathrm{n}$ & \multicolumn{2}{l}{ Survival rate after LPS injection, \% } \\
\cline { 3 - 4 } & & $12 \mathrm{~h}$ & $24 \mathrm{~h}$ \\
\hline wt & 4 & 100 & 0 \\
${\text { casp } 1^{-/-}}$ & 5 & 100 & 100 \\
\hline
\end{tabular}
alive.

At $24 \mathrm{~h}$ all wt mice had died, whereas all casp $1^{-/-}$mice were still

the lethal effects of LPS in a separate experiment. We confirmed that the same LPS serotype and dose used in the present studies caused $100 \%$ lethality in wt mice ( $\mathrm{n}=4$ ) within $12-24 \mathrm{~h}$ after injection, whereas all casp $^{-1-}$ mice $(\mathrm{n}=5)$ were alive at $24 \mathrm{~h}$, which confirmed previous results showing that $100 \%$ of casp $1^{-/-}$ survived for at least $30 \mathrm{~h}$ after receiving the same i.p. dose and serotype of LPS injection [11] (table 2). Figure 1 illustrates gene expression level changes in the hippocampus, spleen and adrenals.

In wt mice, most of the studied genes displayed the highest expression levels (23 out of 24 measurements) at $6 \mathrm{~h}$ after injection $\left(\chi^{2}, \mathrm{p}<0.0001\right)$, except for adrenal Adamts 1 which peaked at $12 \mathrm{~h}$. In casp $1^{-/-}$mice, the highest mRNA levels (19 out of 24 measurements) were also seen at $6 \mathrm{~h}$ after injection $\left(\chi^{2}, \mathrm{p}<0.01\right)$, except for splenic Il1rn, Ptgs2, Nos2 and Adamts1, and adrenal Adamts 1, which peaked at $12 \mathrm{~h}$ (fig. 1). We found that LPS induced significant increases (above baseline levels observed at $0 \mathrm{~h}$ ) in the expression of most of the eight studied genes in the three tissues of both genotypes, except for the splenic expression of Il1rn, Nos2, Ptgs2 and Adamts 1 genes in casp $1^{-/}$mice, and the splenic Ill $\mathrm{rn}$ gene in wt mice (fig. 1; table 3); therefore, four out of the eight genes were not activated in the spleen of casp1deficient mice. Thus, it appears that the temporal expression of the studied genes mostly followed an early and sharp increase pattern similar to that described for proinflammatory elements during the initial stage of the inflammatory response. A summary of the two-way

Fig. 1. mRNA expression pattern of the eight selected genes in the hippocampus, spleen and adrenals of wt and casp $1^{-1-}$ mice. The time-dependent pattern of expression of each gene is shown: Nos2 (a), Ptgs2 (b), Cxcl1 (c), Cxcl10 (d), Tgtp (e), Gbp2 (f), Illrn (g) and Adamts1 (h). The mean expression levels at 0,6 and $12 \mathrm{~h}$ after LPS
ANOVA significance probabilities for the differential expression of each gene within each organ is given in table 3. The following sections provide a brief summary of the gene expression changes for each gene.

\section{Nos2}

Nos2 gene expression was significantly lower at $6 \mathrm{~h}$ in all three casp $1^{-/-}$mice tissues when compared to those of wt mice; it was $30 \%$ lower in the hippocampus $(\mathrm{p}<0.01)$, $75 \%$ lower in the spleen $(\mathrm{p}<0.001)$, and $40 \%$ lower in the adrenals ( $\mathrm{p}<0.001$; fig. 1a). The LPS-induced expression of Nos 2 followed a similar pattern in both genotypes, but of decreased magnitude in casp $1^{-/-}$mice. Both genotypes showed activation of gene expression at $6 \mathrm{~h}$, and a decrease towards baseline at $12 \mathrm{~h}$ (except for Nos 2 expression in wt adrenal, which remained elevated at $12 \mathrm{~h} ; \mathrm{p}<$ 0.01 vs. $0 \mathrm{~h}$ ).

\section{Ptgs2}

The peak Ptgs 2 mRNA level at 6 h was significantly lower by 25 and $75 \%$ in casp $1^{-/-}$mice in the hippocampus $(\mathrm{p}<0.05)$ and the spleen $(\mathrm{p}<0.001)$, respectively, whereas no significant changes were observed within the adrenals of both genotypes (fig. 1b). Ptgs 2 transcriptional patterns were similar to those of Nos2, i.e. Ptgs2 gene expression was increased at $6 \mathrm{~h}$ and returned to baseline values at $12 \mathrm{~h}$.

\section{Cxcl1, Cxcl10 and Tgtp}

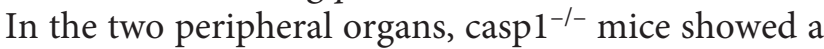
significantly lower and variable magnitude of increases in these three genes compared to wt mice, and casp $1^{-1-}$ mice displayed $30-80 \%$ lower mRNA levels ( $\mathrm{p}<0.05$ to $<0.001$; fig. 1c-e). These genes showed similar transcriptional patterns in the three tissues/organs studied from both genotypes. At the CNS level, their hippocampal expression showed no significant differences between the two genotypes.

\section{Gbp2}

Adrenal mRNA expression of Gbp2 was significantly lower in $\mathrm{casp}^{-/-}$mice than wt mice, by $35 \%$ at $6 \mathrm{~h}(\mathrm{p}<$ 0.001 ; fig. 1f). Thereafter, Gbp2 expression had decreased injection are represented by white and black columns, respectively, for wt and casp $1^{-/-}$mice; the line above represents one standard error of the mean. Statistically significant differences between wt and casp $1^{-1-}$ mice at the same time point are shown: ${ }^{*} \mathrm{p}<0.05$; ** $\mathrm{p}<0.01 ;{ }^{* * *} \mathrm{p}<0.001$.
(For figure see next page.) 


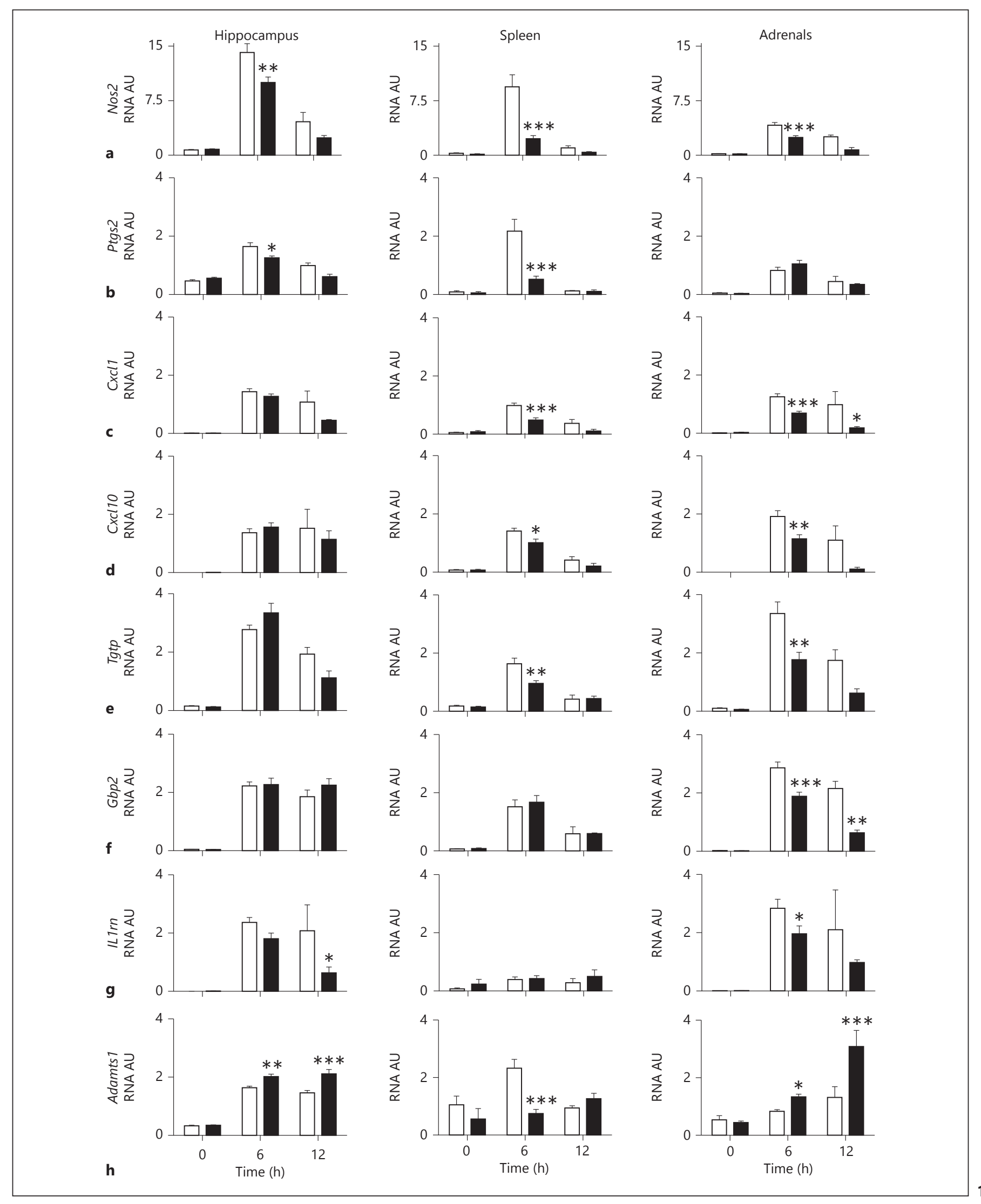


Table 3. Two-way ANOVA summary

\begin{tabular}{|c|c|c|c|c|c|c|c|c|c|c|}
\hline Organ & Gene & \multicolumn{3}{|c|}{ Component } & \multicolumn{3}{|l|}{ wt } & \multicolumn{3}{|l|}{ 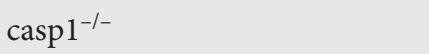 } \\
\hline \multirow{5}{*}{ Hippocampus } & Ptgs 2 & $* *$ & $* * *$ & $*$ & $* * *$ & n.s. & $*$ & $* * *$ & n.s. & $*$ \\
\hline & Cxcl1 & $* *$ & $* * *$ & n.s. & $* * *$ & $* * *$ & n.s. & $* * *$ & n.s. & $* *$ \\
\hline & Cxcl10 & n.s. & $* * *$ & n.s. & $* * *$ & $* * *$ & n.s. & $* * *$ & $*$ & n.s. \\
\hline & Il1rn & $* * *$ & $* * *$ & $*$ & $* * *$ & $* * *$ & n.s. & $* * *$ & n.s. & $*$ \\
\hline & Adamts1 & $* * *$ & $* * *$ & $* * *$ & $* * *$ & $* * *$ & n.s. & $* * *$ & $* * *$ & n.s. \\
\hline \multirow[t]{5}{*}{ Spleen } & Nos 2 & $* * *$ & $* * *$ & $* *$ & $* * *$ & n.s. & $* *$ & n.s. & n.s. & n.s. \\
\hline & Ptgs2 & $* * *$ & $* * *$ & $* *$ & $* * *$ & n.s. & $* *$ & n.s. & n.s. & n.s. \\
\hline & Cxcl1 & $* * *$ & $* * *$ & $* *$ & $* * *$ & n.s. & $* *$ & $* *$ & n.s. & n.s. \\
\hline & Il1rn & n.s. & n.s. & n.s. & n.s. & n.s. & n.s. & n.s. & n.s. & n.s. \\
\hline & Adamts1 & $* * *$ & $*$ & $*$ & $*$ & n.s. & n.s. & n.s. & n.s. & n.s. \\
\hline \multirow[t]{8}{*}{ Adrenals } & Nos 2 & $* * *$ & $* * *$ & $*$ & $* * *$ & $* *$ & n.s. & $* * *$ & n.s. & $*$ \\
\hline & Ptgs2 & n.s. & $* * *$ & $*$ & $* *$ & $* *$ & n.s. & $* * *$ & n.s. & n.s. \\
\hline & Cxcl1 & $* * *$ & $* * *$ & $* *$ & $* * *$ & $* * *$ & n.s. & $* * *$ & n.s. & n.s. \\
\hline & Cxcl10 & $* * *$ & $* * *$ & $*$ & $* * *$ & $*$ & n.s. & $* * *$ & n.s. & $*$ \\
\hline & Tgtp & $* * *$ & $* * *$ & $*$ & $* * *$ & n.s. & n.s. & $*$ & n.s. & n.s. \\
\hline & $G b p 2$ & $* * *$ & $* * *$ & $* *$ & $* * *$ & $* * *$ & n.s. & $* * *$ & n.s. & $* *$ \\
\hline & Il1rn & $* * *$ & $* * *$ & n.s. & $* * *$ & $*$ & n.s. & $* * *$ & n.s. & n.s. \\
\hline & Adamts1 & $* * *$ & $* * *$ & $* * *$ & n.s. & $*$ & n.s. & $* * *$ & $* * *$ & $* * *$ \\
\hline
\end{tabular}

The significance of the three major components (genotype, time and interaction) is shown for the eight genes in each of the tissues studied. $\mathrm{p}$ values are family-wise corrected. The comparison among time points within genotypes is also shown for wt and casp $1^{-/-}$ mice. Statistically significant differences between time points are shown: ${ }^{*} \mathrm{p}<0.05 ;{ }^{* *} \mathrm{p}<0.01 ;{ }^{* * *} \mathrm{p}<0.001$. n.s. $=$ Not significant. Bold n.s. indicates no increased expression when compared with 0 h. For example, splenic expression of Nos2, Ptgs 2 and Adamts1 remained significantly unchanged in casp $1^{-/-}$mice, whereas the splenic expression of Ill rn remained significantly unchanged in both genotypes.

in both genotypes at $12 \mathrm{~h}$ to similar levels. Hippocampal and splenic $G b p 2$ expression levels showed no genotype differences.

\section{Il1rn}

In the hippocampus of both genotypes, LPS elicited similarly large Ill $\mathrm{rn}$ expression increases at $6 \mathrm{~h}$. At $12 \mathrm{~h}$, Ill $\mathrm{rn}$ mRNA remained elevated in wt mice and declined by $70 \%$ in casp $1^{-/-}$mice ( $\leq 50.05$; fig. $1 \mathrm{~g}$ ). Adrenal Il1 rn activation for both genotypes was similar to that of the hippocampus, reaching significantly larger increases of $40 \%$ at $6 \mathrm{~h}(\mathrm{p}<0.05)$ and of $115 \%$ at $12 \mathrm{~h}(\mathrm{p}<0.001)$ in wt mice. Splenic Ill $r n$ mRNA expression was unchanged in both genotypes.

\section{Adamts1}

Surprisingly, hippocampal Adamts1 mRNA expression was of a higher magnitude in casp $1^{-/-}$mice, increased by $23 \%$ at $6 \mathrm{~h}(\mathrm{p} \leq 0.01)$ and $45 \%$ at $12 \mathrm{~h}(\mathrm{p}<0.001$; fig. $1 \mathrm{~h})$, and followed a similar temporal pattern in wt and casp $1^{-/-}$ mice. Adrenal Adamts1 expression was also larger in casp $^{-/-}$mice: they were $50 \%$ higher at $6 \mathrm{~h}(\mathrm{p}<0.05)$ and 2.3 -fold higher at $12 \mathrm{~h}(\mathrm{p}<0.001)$. Splenic Adamts 1 mRNA expression increased significantly at $6 \mathrm{~h}$ and returned to baseline levels at $12 \mathrm{~h}$ in wt mice, whereas no changes above baseline were observed in casp $^{-/-}$mice. The genotype comparison showed that splenic Adamts 1 mRNA levels were $70 \%$ lower in casp $1^{-/-}$mice at $6 \mathrm{~h}(\mathrm{p}<$ $0.001)$. 


\section{Correlation Analysis}

Hippocampus

All correlations between hippocampal mRNA expression levels of the genes studied were significant within each genotype; however, correlation coefficients comparing genotypes (wt vs. casp $1^{-/-}$mice) showed significant differences only between Tgtp/Gbp2 ( $\mathrm{p}_{\mathrm{FDR}}$ $<0.05$ ) and Tgtp/Adamts1 ( $\mathrm{p}_{\mathrm{FDR}}<0.01$; online suppl. fig. 1S; for all online suppl. material, see www.karger. com/doi/10.1159/000368310).

\section{Spleen}

In wt mice, correlation analyses of splenic mRNA levels were significant, except for all Illrn correlations (online suppl. fig. 2S). In casp $1^{-1-}$ mice, most splenic mRNA level correlations were significant, and most Ill rn and Adamts 1 correlations were not significant, except for the correlation between Il1 rn and Adamts1, which was significant (online suppl. fig. 2S). Splenic correlation coefficients comparing genotype showed that only three coefficient pairs, all related to Adamts1, were significantly different: Ptgs2 and Adamts1 ( $\mathrm{p}_{\mathrm{FDR}}<0.001$ ), Nos2 and Adamts 1 ( $\left.\mathrm{p}_{\mathrm{FDR}}=0.006\right)$, and Gbp2 and Adamts1 ( $\mathrm{p}_{\mathrm{FDR}}=$ 0.018 ; online suppl. fig. $2 S$ ).

\section{Adrenals}

Correlation analysis of adrenal mRNA levels showed that all correlations were significant in wt mice, except for Nos2 and Adamts1, whereas six pairs of correlations related to Adamts1 were not significant in $\mathrm{casp}^{-/-}$mice: Ptgs2 and Adamts1, Nos2 and Adamts1, Cxcl1 and Adamts1, Cxcl10 and Adamts1, Tgtp and Adamts1, and Gbp2 and Adamts1. Adrenal correlation coefficients comparing genotypes did not show any significant differences (online suppl. fig. 3S). Overall, there was a loss of correlation for the Adamts1 gene in peripheral tissues in casp1-deficient mice.

\section{Hierarchical Clustering}

This analysis was done to ascertain patterns of gene coexpression using clustering strategies by comparing: (i) the same tissue between wt and casp $1^{-/-}$mice, and (ii) the three tissues within the same genotype (fig. 2).

\section{Clustering Comparison between wt and casp $1^{-/-}$}

Mice

In the hippocampus (fig. 2a, b), two clusters were supported at the $95 \% \mathrm{CI}$ level in wt animals. The first cluster was comprised of the Cxcl10 and Il1rn genes, whereas the second was defined by the Gbp2, Tgtp and Adamts1 genes (fig. 2a, b). Interestingly, no clusters were supported at the $95 \%$ level in casp $1^{-/-}$mice (fig. 2a, b). There were qualitative similarities between splenic data of both genotypes (fig. 2c, d). In the spleen of wt mice, all genes except the Illrn gene formed one cluster (fig. 2c, d), whereas in casp $^{-1-}$ mice, two clusters were supported at the $95 \%$ level (the Cxcl1 and Cxcl10 cluster, and the Ptgs2, Gbp2, Nos2 and Tgtp cluster; fig. 2d). High similarities were found between adrenal data from wt and casp $1^{-/-}$mice: they had one cluster consisting of six and seven genes, respectively, at a 95\% significance level. The Ptgs2 (in wt mice) and the Adamts 1 (in wt and casp1 $1^{-/-}$mice) genes were not included in the clusters (fig. 2f).

\section{Clustering Comparison among Tissues}

More similarities were found between the two peripheral organs (spleen and adrenals) than between those tissues and the hippocampus. In wt mice, five genes were coexpressed both within the spleen and adrenals (Gbp2, Tgtp, Cxcl1, Cxcl10 and Nos2). In casp1 $1^{-/}$mice, six out of the seven genes that clustered together within the adrenal gland were divided into two clusters (one with two genes, Cxcl1 and Cxcl10, and another with four genes Ptgs2, Gbp2, Nos2 and Tgtp) in the spleen. There were two clusters within the hippocampus of wt mice. One of them showed a coexpression of two genes (Cxcl10 and Ill rn) that were also shown to be coexpressed in the adrenals of wt mice (fig. 2a, $b, e, f)$. The other cluster within the brain of wt mice displayed three genes that were also shown to be coexpressed within the spleen (fig. 2a-d). Overall, at the 95\% level, $A d$ amts 1 did not coexpress with any gene in casp $1^{-/-}$mice tissues, while in wt it coexpressed in 2 of the 3 tissues.

\section{Discussion}

We used LPS-induced SIRS in casp1-deficient mice to detail patterns of gene expression that may contribute to their resilience to LPS-induced lethality, which could lead to the development of novel therapeutic targets for SIRS. In this study, we described central and peripheral changes in the expression of a set of eight genes in the context of casp1 deficiency and a lethal dose of LPS, and showed that endotoxin elicited an inflammatory cascade of much lower magnitude in casp $1^{-/-}$mice. Overall, these changes occurred in a time-dependent manner, with peak mRNA expression of most genes occurring $6 \mathrm{~h}$ after LPS injection, and declining to baseline levels by $12 \mathrm{~h}$. In previous studies we have shown evidence suggesting that activated transcripts during inflammation show two 


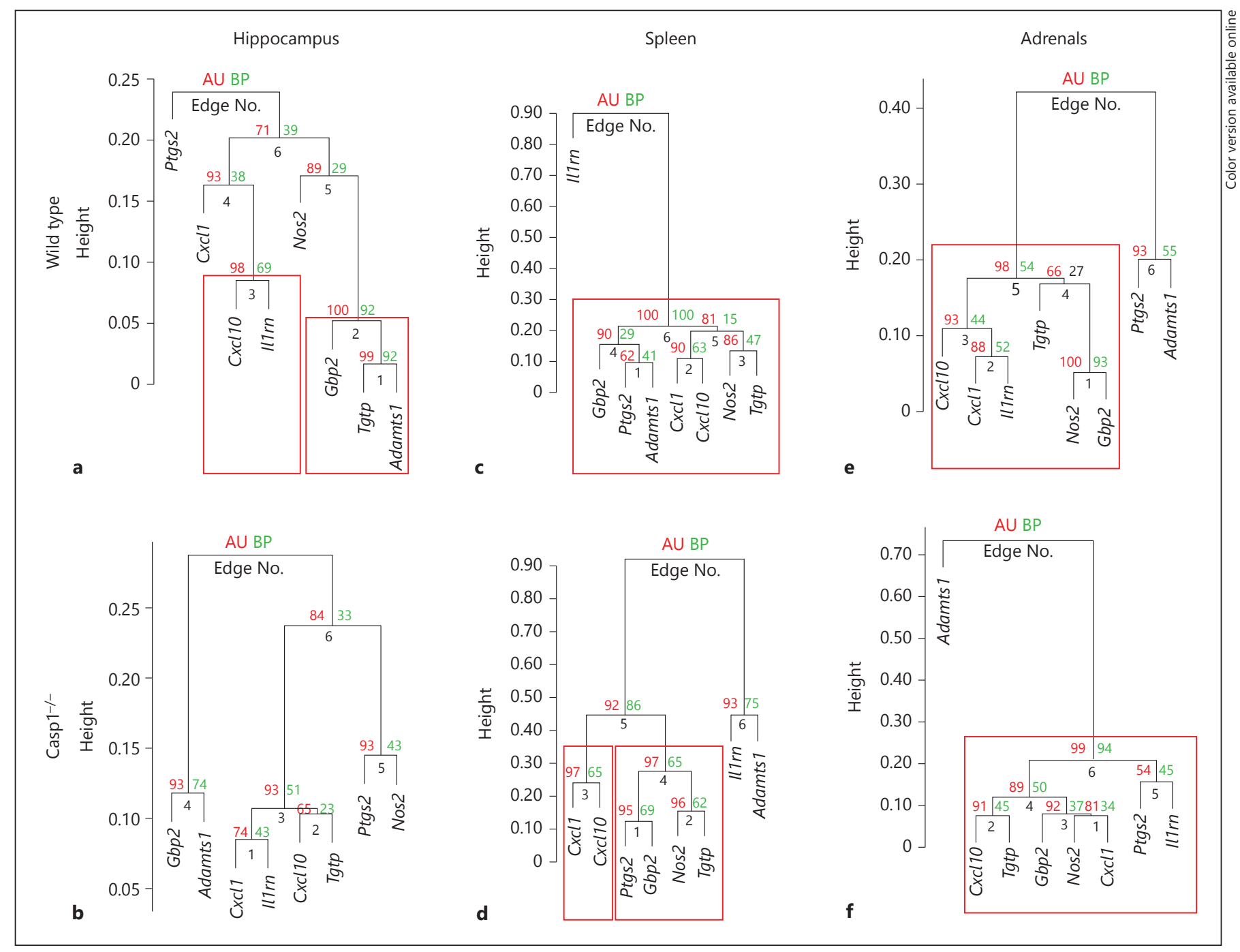

Fig. 2. Hierarchical cluster analysis of gene expression levels with $\mathrm{AU}$ - and BP-based p values (in red and green, respectively; colors refer to the online version only). The vertical distance between the gene expression levels indicate how dissimilar they are. Results for hippocampus (a, b), spleen $(\mathbf{c}, \mathbf{d})$ and adrenal tissues $(\mathbf{e}, \mathbf{f})$ are presented in wt $(\mathbf{a}, \mathbf{c}, \mathbf{d})$ and casp $1^{-/-}(\mathbf{b}, \mathbf{d}, \mathbf{f})$ mice. The genes shown inside the red boxes clustered together according to an AU probability set at $\geq 95 \%$ level, after bootstrap resampling. types of temporal patterns: transient and sustained [23]. With exception of Illrn, it appears that within the spleen most of the genes followed a transient pattern of increase by augmenting at $6 \mathrm{~h}$ and returning to baseline at $12 \mathrm{~h}$, whereas most of the genes seemed to follow a more sustained pattern of activation in the hippocampus and adrenals, which lasted for at least $12 \mathrm{~h}$.

The most contrasting changes in gene expression between both genotypes occurred in the spleen. After LPS injection, the splenic expression of three genes, namely Nos2, Ptgs2 and Adamts1, was largely increased in wt mice, whereas it was not significantly altered in $\mathrm{casp}^{-/-}$mice.
There are a couple of exceptions to the generalized idea that the inflammatory cascade elicited by LPS was of a lower magnitude in casp $1^{-/-}$mice. For instance, we found that the expression of Adamts1 remained significantly increased in the hippocampus and adrenals of casp1-deficient mice.

Our previous work suggested that the expression of these eight genes was controlled by casp1 [12]. In order to study gene-gene interactions, we evaluated their relationship by performing correlation and hierarchical clustering analyses. There was an overall loss of correlation for the Adamts1 gene in peripheral tissues of casp $1^{-/}$ mice. Differences observed in the hierarchical clustering 
analyses seem to support that casp 1 deficiency altered the coexpression of these genes in a more significant manner within the brain than in the peripheral organs. Indeed, these analyses revealed similar clusters within the adrenals and the spleen of wt and casp $1^{-/-}$mice, whereas no similarities were evident in the hippocampus of both genotypes. In addition, coexpression analyses showed more similarities between peripheral organs (spleen and adrenals) than between these peripheral organs and the hippocampus; there was also a tendency of coexpression loss for Adamts1 in casp $1^{-/-}$mice.

Products of three out of the eight genes reported here, specifically the Nos2, Ptgs2 and Illm genes, have been pharmacologically targeted in preclinical and clinical trials of SIRS/sepsis. The inhibition of nitric oxide (NO) synthesis, a free radical largely synthesized by NOS2 during SIRS/sepsis, improved hemodynamic parameters in immunologically challenged rodents and septic patients [2430]. However, multicenter randomized placebo-controlled studies showed that the mortality rate of septic shock patients treated with NOS inhibitors was not improved $[29,30]$. Similarly, preclinical studies largely support the concept that pharmacological inhibition of cyclooxygenase and/or genetic ablation of PTGS2 resulted in beneficial effects on mortality [31]. Unfortunately, the beneficial effects of cyclooxygenase inhibition observed in preclinical studies have so far not been convincingly and consistently translated into the clinical setting [32-34]. Only a sub-study from one clinical trial showed a significant reduction in the 30-day mortality rate of sepsis [35]. Studies involving IL-1 $\mathrm{ra}$ also yielded promising outcomes in preclinical trials [36]. Likewise casp $1^{-/-}$mice, overexpressing IL-1ra have also shown resilience to LPS-induced lethality [36]. In both casp $1^{-/}$and IL-1ra-overexpressing mice, the resilience to LPS-induced lethality was observed for at least 6 and 7 days, respectively, indicating that in these two strains of mice the improvement in survival was long lasting $[11,36]$. However, these results could not be effectively translated into the clinical setting as rhIL1ra failed to reduce sepsis mortality $[37,38]$.

The contribution of the products of the other five genes that were also differentially expressed between wt and casp $1^{-/-}$mice has not been clearly ascertained in preclinical/clinical studies of SIRS/sepsis. Two of them are the chemokines Cxcl1 and Cxcl10. Chemokines and their receptors are expressed in immune and endothelial cells, and play a fundamental role in recruiting immune cells into the inflammatory site $[39,40]$. Therefore, the reduced expression of $\mathrm{Cxcl} 1$ and $\mathrm{Cxcl} 10$ observed in casp $1^{-/-}$ mice could have contributed to a better outcome against
LPS-induced lethality due to decreased immune cell recruitment.

We also investigated the expression of the GTPases Tgtp and $G b p 2$, another two genes that were differentially expressed between casp $1^{-/-}$and wt mice. These two interferon-induced GTPases are expressed in immune cells, but their roles in SIRS/sepsis have not been clearly ascertained [41-43]. Overall, guanylate binding proteins have been characterized as downstream effectors of the interferon signaling pathway [44]. They play essential roles in fighting intracellular pathogens [44]. A recent study showed that intracellular LPS from Gram-negative bacteria activated guanylate-binding proteins, which in turn participated in a programmed cell death pathway termed pyroptosis [45]. Since we employed a large dose of LPS, it is likely that increased cytosolic accumulation of endotoxin could activate guanylate-binding protein-induced pyroptosis. Thus, their decreased expression in casp $1^{-/-}$mice could result in decreased inflammation and, consequently, in improved survival after being exposed to a lethal dose of endotoxin. However, further studies need to be performed to elucidate the roles of GBP2 and TGTP during SIRS.

Finally, ADAMTS1, an enzyme that belongs to the family of the metalloproteases, was also differentially expressed between the two genotypes. ADAMTS1 is necessary for normal growth, female fertility and kidney, adrenal and female reproductive organ structure and function [46]. Recently, it was shown that LPS dramatically increased the synthesis of ADAMTS1 within the splenic lymph and interstitial fluid to a concentration that was much higher than that of plasma, suggesting that the spleen is a major source of ADAMTS1, and that this metalloprotease is involved in the endotoxin-induced disease process [47]. Within the brain, metalloproteases play a key role in controlling blood-brain barrier permeability during LPS-induced inflammation, and ADAMTS1 may have a role in regulating neural plasticity, as null female mice have a selective decline of synaptic protein levels in the frontal cortex [48].

There are apparent discrepancies between our current and previous studies. In our previous study, the transcriptional differences between both genotypes appeared to occur specifically within the brain, and not in the periphery, since both wt and casp $1^{-/-}$mice showed similar LPS-induced increases in their expression level within the spleen [12]. In this study, we found that only the hippocampal transcriptional expression of two out of the eight genes, Nos2 and Ptgs2, showed similar differences to those previously reported in the whole brain of both genotypes [12]. These differences could be due to the fact that we previ- 
ously employed a lower dose and less inflammatory serotype of LPS (e.g. E. coli 055:B5, $25 \mathrm{mg} / \mathrm{kg}$ ) than the one employed in this study [12]. The previous dose and serotype of LPS was shown to cause a slower progression towards death in wt mice (100\% mortality after 5 days of injection) [49] than the LPS dose and serotype reported here (100\% mortality within approximately 1.25 days) [11]. Furthermore, in our previous studies we employed whole brains [12], whereas here we used hippocampi. Moreover, we studied a small group of mice at $12 \mathrm{~h}$ after LPS injection, and this could have lowered the statistical power to detect differences at that particular time point.

It was recently shown that casp1-targeted mice carry a 129 ES cell-derived mutation in the casp 11 gene, which appeared to be involved, at least in part, in their resilience to LPS-induced lethality [50]. The synergistic key role of two of the downstream effectors controlled by casp1, namely IL-18 and IL- $1 \beta$, during LPS-induced lethality was recently shown [51]. The survival rate of casp $1 / 11^{-/-}$ was very similar to that of IL- $1 \beta / \mathrm{IL}$-18-deficient mice after receiving an $\mathrm{LD}_{100}$ of LPS of the same serotype as the one used in the present studies [51]. The latter results clearly highlight the relevance of the casp1-orchestrated pathway during LPS-induced SIRS. However, when casp $1 / 11^{-/-}$and IL-1 $\beta /$ IL-18-deficient mice were subjected to other immunological challenges, such as the cecal ligation and puncture procedure or the administration of a lethal dose of tumor necrosis factor- $\alpha$, casp $1 / 11^{-/-}$displayed a lower survival rate than IL-1 $\beta /$ IL-18-deficient mice, indicating that targeting downstream effectors could be more efficacious than inhibiting the upstream activators CASP1 or CASP11 [51].

In summary, we described tissue and time-dependent expression profiles of a set of genes regulated by casp- 1 after LPS-induced SIRS. Our data suggest that three elements may contribute to casp $1^{-/-}$mice resilience to SIRS-induced lethality: (1) a decreased inflammatory cascade due to a lower expression of casp1-orchestrated genes and a faster resolution of the proinflammatory process, (2) increased Adamts1 activation in the hippocampus, which could potentially increase neural plasticity, and (3) loss of gene-gene interaction in the hippocampus. Future studies need to confirm whether changes in CNS gene-gene interactions or ADAMTS1 biological activity are associated with the increased survival of casp $1^{-/}$mice after a lethal dose of LPS. Additionally, we will examine whether inhibitors of casp1 activity promote similar changes in genetic expression. The elucidation of these transcription pattern changes could provide a foundation for the development of molecular biomarkers and therapeutic targets against SIRS/sepsis.

\section{Acknowledgments}

This research was supported in part by a National Institutes of Health grant K24RR017365 to M.L.W., and by institutional funds from the University of Miami and the Australian National University. The funders had no role in the study design, data collection and analysis, decision to publish or preparation of the manuscript.

\section{References}

-1 Takala A, Nupponen I, Kylanpaa-Back ML, Repo H: Markers of inflammation in sepsis. Ann Med 2002;34:614-623.

$\checkmark 2$ Hotchkiss RS, Karl IE: The pathophysiology and treatment of sepsis. N Engl J Med 2003; 348:138-150.

$\checkmark 3$ Wong ML, Xie B, Beatini N, Phu P, Marathe S, Johns A, Gold PW, Hirsch E, Williams KJ, LicinioI J, Tabas I: Acute systemic inflammation up-regulates secretory sphingomyelinase in vivo: a possible link between inflammatory cytokines and atherogenesis. Proc Natl Acad Sci U S A 2000;97: 8681-8686.

-4 Mastronardi CA, Srivastava V, Yu WH, Les Dees W, McCann SM: Lipopolysaccharideinduced leptin synthesis and release are differentially controlled by $a$-melanocytestimulating hormone. Neuroimmunomodulation 2005; 12:182-188.

5 Mastronardi CA, Yu WH, McCann S: Lipopolysaccharide-induced tumor necrosis factor- $\alpha$ release is controlled by the central nervous system. Neuroimmunomodulation 2001;9:148-156.

6 Mastronardi CA, Yu WH, Rettori V, McCann S: Lipopolysaccharide-induced leptin release is not mediated by nitric oxide, but is blocked by dexamethasone. Neuroimmunomodulation 2000;8:91-97.

7 Wong ML, Bongiorno PB, Rettori V, McCann SM, Licinio J: Interleukin (IL) $1 \beta$, IL-1 receptor antagonist, IL-10, and IL-13 gene expression in the central nervous system and anterior pituitary during systemic inflammation: pathophysiological implications. Proc Natl Acad Sci U S A 1997;94:227-232.

$>8$ Wong M-L, Rettori V, Al-Shekhlee A, Bongiorno PB, Canteros G, McCann SM, Gold PW, Licinio J: Inducible nitric oxide synthase gene expression in the brain during systemic inflammation. Nature Med 1996;2:581-584.

9 Mastronardi CA, Yu WH, Srivastava VK, Dees WL, McCann SM: Lipopolysaccharide-induced leptin release is neurally controlled. Proc Natl Acad Sci U S A 2001;98:14720-14725.
10 Wong ML, O’Kirwan F, Khan N, Hannestad J, Wu KH, Elashoff D, Lawson G, Gold PW, McCann SM, Licinio J: Identification, characterization, and gene expression profiling of endotoxin-induced myocarditis. Proc Natl Acad Sci U S A 2003;100:14241-14246.

11 Li P, Allen H, Banerjee S, Franklin S, Herzog L, Johnston C, McDowell J, Paskind M, Rodman L, Salfeldet J, et al: Mice deficient in IL$1 \beta$-converting enzyme are defective in production of mature IL-1 $\beta$ and resistant to endotoxic shock. Cell 1995;80:401-411.

12 Mastronardi C, Whelan F, Yildiz OA, Hannestad J, Elashoff D, McCann SM, Licinio J, Wong ML: Caspase 1 deficiency reduces inflammation-induced brain transcription. Proc Natl Acad Sci U S A 2007;104: 7205-7210.

13 Chesnokova V, Melmed S: Minireview: neuro-immuno-endocrine modulation of the hypothalamic-pituitary-adrenal (HPA) axis by gp130 signaling molecules. Endocrinology 2002;143:1571-1574. 


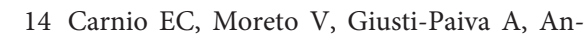
tunes-Rodrigues J: Neuro-immune-endocrine mechanisms during septic shock: role for nitric oxide in vasopressin and oxytocin release. Endocr Metab Immune Disord Drug Targets 2006;6:137-142.

15 Chrousos GP: The hypothalamic-pituitaryadrenal axis and immune-mediated inflammation. New Engl J Med 1995;332:1351-1362.

16 Tracey KJ: Physiology and immunology of the cholinergic antiinflammatory pathway. J Clin Invest 2007;117:289-296.

17 De Kloet ER, Vreugdenhil E, Oitzl MS, Joels M: Brain corticosteroid receptor balance in health and disease. Endocr Rev 1998;19:269-301.

-18 Schobitz B, Sutanto W, Carey MP, Holsboer F, de Kloet ER: Endotoxin and interleukin $1 \mathrm{de}-$ crease the affinity of hippocampal mineralocorticoid (type I) receptor in parallel to activation of the hypothalamic-pituitary-adrenal axis. Neuroendocrinology 1994;60:124-133.

-19 Bener D, Wohlman A, Itzik A, Yirmiya R, Ben-Hur T, Weidenfeld J: Glucocorticoid resistance following herpes simplex-1 infection: role of hippocampal glucocorticoid receptors. Neuroendocrinology 2007;85:207-215.

-20 Yao JH, Ye SM, Burgess W, Zachary JF, Kelley KW, Johnson RW: Mice deficient in interleukin- $1 \beta$ converting enzyme resist anorexia induced by central lipopolysaccharide. Am J Physiol 1999;277:R1435-R1443.

21 Benjamini Y, Hochberg Y: Controlling the false discovery rate: a practical and powerful approach to multiple testing. J R Stat Soc Ser B 1995;57:289-300.

22 Suzuki R, Shimodaira H: Pvclust: an R package for assessing the uncertainty in hierarchical clustering. Bioinformatics 2006;22:15401542.

23 Mastronardi CA, Licinio J, Wong ML: Candidate biomarkers for systemic inflammatory response syndrome and inflammation: a pathway for novel translational therapeutics. Neuroimmunomodulation 2010;17:359-368.

24 Thiemermann C, Vane J: Inhibition of nitric oxide synthesis reduces the hypotension induced by bacterial lipopolysaccharides in the rat in vivo. Eur J Pharmacol 1990;182:591-595.

25 Kilbourn RG, Gross SS, Jubran A, Adams J, Griffith OW, Levi R, Lodato RF: NG-methyl-L-arginine inhibits tumor necrosis factorinduced hypotension: implications for the involvement of nitric oxide. Proc Natl Acad Sci U S A 1990;87:3629-3632.

26 Petros A, Bennett D, Vallance P: Effect of nitric oxide synthase inhibitors on hypotension in patients with septic shock. Lancet 1991; 338:1557-1558.

-27 Petros A, Lamb G, Leone A, Moncada S, Bennett D, Vallance P: Effects of a nitric oxide synthase inhibitor in humans with septic shock. Cardiovasc Res 1994;28:34-39.

28 Avontuur JA, Tutein Nolthenius RP, van Bodegom JW, Bruining HA: Prolonged inhibition of nitric oxide synthesis in severe septic shock: a clinical study. Crit Care Med 1998;26: 660-667.
29 Lopez A, Lorente JA, Steingrub J, Bakker J, McLuckie A, Willatts S, Brockway M, Anzueto A, Holzapfel L, Breen D, Silverman MS, Takala J, Donaldson J, Arneson C, Grove G, Grossman S, Grover R: Multiple-center, randomized, placebo-controlled, double-blind study of the nitric oxide synthase inhibitor 546C88: effect on survival in patients with septic shock. Crit Care Med 2004;32:21-30.

30 Kinasewitz GT, Privalle CT, Imm A, Steingrub JS, Malcynski JT, Balk RA, DeAngelo J: Multicenter, randomized, placebo-controlled study of the nitric oxide scavenger pyridoxalated hemoglobin polyoxyethylene in distributive shock. Crit Care Med 2008;36:1999-2007.

31 Aronoff DM: Cyclooxygenase inhibition in sepsis: is there life after death? Mediators Inflamm 2012;2012:696897.

32 Bernard GR, Wheeler AP, Russell JA, Schein R, Summer WR, Steinberg KP, Fulkerson WJ, Wright PE, Christman BW, Dupont WD, Higgins SB, Swindell BB: The effects of ibuprofen on the physiology and survival of patients with sepsis. New Engl J Med 1997;336:912-918.

-33 Haupt MT, Jastremski MS, Clemmer TP, Metz CA, Goris GB: Effect of ibuprofen in patients with severe sepsis: a randomized, doubleblind, multicenter study. The Ibuprofen Study Group. Crit Care Med 1991;19:1339-1347.

34 Memis D, Karamanlioglu B, Turan A, Koyuncu O, Pamukcu Z: Effects of lornoxicam on the physiology of severe sepsis. Crit Care 2004;8:R474-R482.

- 35 Arons MM, Wheeler AP, Bernard GR, Christman BW, Russell JA, Schein R, Summer WR, Steinberg KP, Fulkerson W, Wright P, Dupont WD, Swindell BB: Effects of ibuprofen on the physiology and survival of hypothermic sepsis. Ibuprofen in Sepsis Study Group. Crit Care Med 1999;27:699-707.

36 Hirsch E, Irikura VM, Paul SM, Hirsh D: Functions of interleukin 1 receptor antagonist in gene knockout and overproducing mice. Proc Natl Acad Sci U S A 1996;93:11008-11013.

37 Opal SM, Fisher CJ Jr, Dhainaut JF, Vincent JL, Brase R, Lowry SF, Sadoff JC, Slotman GJ, Levy H, Balk RA, Shelly MP, Pribble JP, LaBrecque JF, Lookabaugh J, Donovan H, Dubin H, Baughman R, Norman J, DeMaria E, Matzel K, Abraham E, Seneff M: Confirmatory interleukin-1 receptor antagonist trial in severe sepsis: a phase III, randomized, double-blind, placebo-controlled, multicenter trial. The Interleukin-1 Receptor Antagonist Sepsis Investigator Group. Crit Care Med 1997;25:1115-1124.

38 Fisher CJ Jr, Opal SM, Lowry SF, Sadoff JC, LaBrecque JF, Donovan HC, Lookabaugh JL, Lemke J, Pribble JP, Stromattet SC, et al: Role of interleukin-1 and the therapeutic potential of interleukin-1 receptor antagonist in sepsis. Circ Shock 1994;44:1-8.

39 Puneet P, Moochhala S, Bhatia M: Chemokines in acute respiratory distress syndrome. Am J Physiol Lung Cell Mol Physiol 2005;288: L3-L15.

40 Oynebraten I, Bakke O, Brandtzaeg P, Johansen FE, Haraldsen G: Rapid chemokine secretion from endothelial cells originates from 2 distinct compartments. Blood 2004;104:314-320.

41 Carlow DA, Teh SJ, Teh HS: Specific antiviral activity demonstrated by TGTP, a member of a new family of interferon-induced GTPases. J Immunol 1998;161:2348-2355.

42 Carlow DA, Marth J, Clark-Lewis I, Teh HS: Isolation of a gene encoding a developmentally regulated $\mathrm{T}$ cell-specific protein with a guanine nucleotide triphosphate-binding motif. J Immunol 1995;154:1724-1734.

43 Lafuse WP, Brown D, Castle L, Zwilling BS: Cloning and characterization of a novel cDNA that is IFN- $\gamma$-induced in mouse peritoneal macrophages and encodes a putative GTPbinding protein. J Leukoc Biol 1995;57:477483.

44 MacMicking JD: IFN-inducible GTPases and immunity to intracellular pathogens. Trends Immunol 2004;25:601-609.

45 Pilla DM, Hagar JA, Haldar AK, Mason AK, Degrandi D, Pfeffer K, Ernst RK, Yamamoto M, Miao EA, Coers J: Guanylate binding proteins promote caspase-11-dependent pyroptosis in response to cytoplasmic LPS. Proc Natl Acad Sci U S A 2014;111:6046-6051.

-46 Shindo T, Kurihara H, Kuno K, Yokoyama H, Wada T, Kurihara Y, Imai T, Wang Y, Ogata M, Nishimatsu H, Moriyama N, Oh-hashi Y, Morita H, Ishikawa T, Nagai R, Yazaki Y, Matsushima K: ADAMTS-1: a metalloproteinase-disintegrin essential for normal growth, fertility, and organ morphology and function. J Clin Invest 2000;105:1345-1352.

47 Oveland E, Karlsen TV, Haslene-Hox H, Semaeva E, Janaczyk B, Tenstad O, Wiig H: Proteomic evaluation of inflammatory proteins in rat spleen interstitial fluid and lymph during LPS-induced systemic inflammation reveals increased levels of ADAMST1. J Proteome Res 2012;11:5338-5349.

48 Howell MD, Torres-Collado AX, Iruela-Arispe ML, Gottschall PE: Selective decline of synaptic protein levels in the frontal cortex of female mice deficient in the extracellular metalloproteinase ADAMTS1. PLoS One 2012;7:e47226.

49 Lee JH, Jung HS, Giang PM, Jin X, Lee S, Son PT, Lee D, Hong YS, Lee K, Lee JJ: Blockade of nuclear factor- $\mathrm{\kappa B}$ signaling pathway and anti-inflammatory activity of cardamomin, a chalcone analog from Alpinia conchigera. J Pharmacol Exp Ther 2006;316:271-278.

50 Kayagaki N, Warming S, Lamkanfi M, Vande Walle L, Louie S, Dong J, Newton K, Qu Y, Liu J, Heldens S, Zhang J, Lee WP, Roose-Girma M, Dixit VM: Non-canonical inflammasome activation targets caspase-11. Nature 2011; 479:117-121.

51 Vanden Berghe T, Demon D, Bogaert P, Vandendriessche B, Goethals A, Depuydt B, Vuylsteke M, Roelandt R, Van Wonterghem E, Vandenbroecke J, Choi SM, Meyer E, Krautwald S, Declercq W, Takahashi N, Cauwels A, Vandenabeele P: Simultaneous targeting of IL-1 and IL-18 is required for protection against inflammatory and septic shock. Am J Respir Crit Care Med 2014;189:282-291. 